\title{
Development of fatigue cracks from mechanically machined scratches on 2024-T351 aluminium alloy-Part I: experimentation and fractographic analysis
}

\author{
A. Cini ${ }^{\mathrm{a}, 1, *}$, P.E. Irving ${ }^{\mathrm{a}}$ \\ a Damage Tolerance group, Department of Materials, Cranfield University, College Road, MK43 0AL, \\ Bedfordshire, UK \\ ${ }^{1}$ Present address: Institute for Advanced Manufacturing, Department of Mechanical, Materials and Manufacturing \\ Engineering, University of Nottingham, University Park, NG7 2RD, Nottingham, UK \\ * Corresponding author. Tel.: +44-(0)115-9514181 \\ E-mail address: andrea.cini@nottingham.ac.uk (A. Cini) \\ p.e.irving@cranfield.ac.uk (P.E. Irving)
}




\section{Abstract}

Clad and unclad 2024-T351 aluminium alloy sheets, weakened by mechanically machined scratches, were fatigued to investigate the effect of small surface damage, like scribe marks, on aircraft fuselage joints. The role of scratch cross section geometry on fatigue life of scribed components was analysed. Scratches between 25 and $185 \mu \mathrm{m}$ deep, with 5 , 25 and $50 \mu \mathrm{m}$ root radii were cut on samples surface using diamond tipped tools. After testing fracture surfaces were examined using a SEM and crack growth rates were measured by striation counting. Scratches reduced aluminium fatigue life under tensile and bending load up to $97.8 \%$ due to multiple cracks nucleation at their roots. Short cracks, nucleated from sharp scratches coalesced to form unique elongated cracks growing through sample thickness. Cracks initiated from scratches were typical short cracks, growing faster than conventional long cracks. Despite the different scribing process, fatigue data of regular diamond tool cut scribes can be used to conservatively predict life reduction owing to ploughed in-service scribe marks on fuselage joints. FE analyses on scribed samples and the fatigue life prediction models are described in Part II of this paper.

Keywords: Notch fatigue; scratches and scribe marks; small cracks; fractography; striations

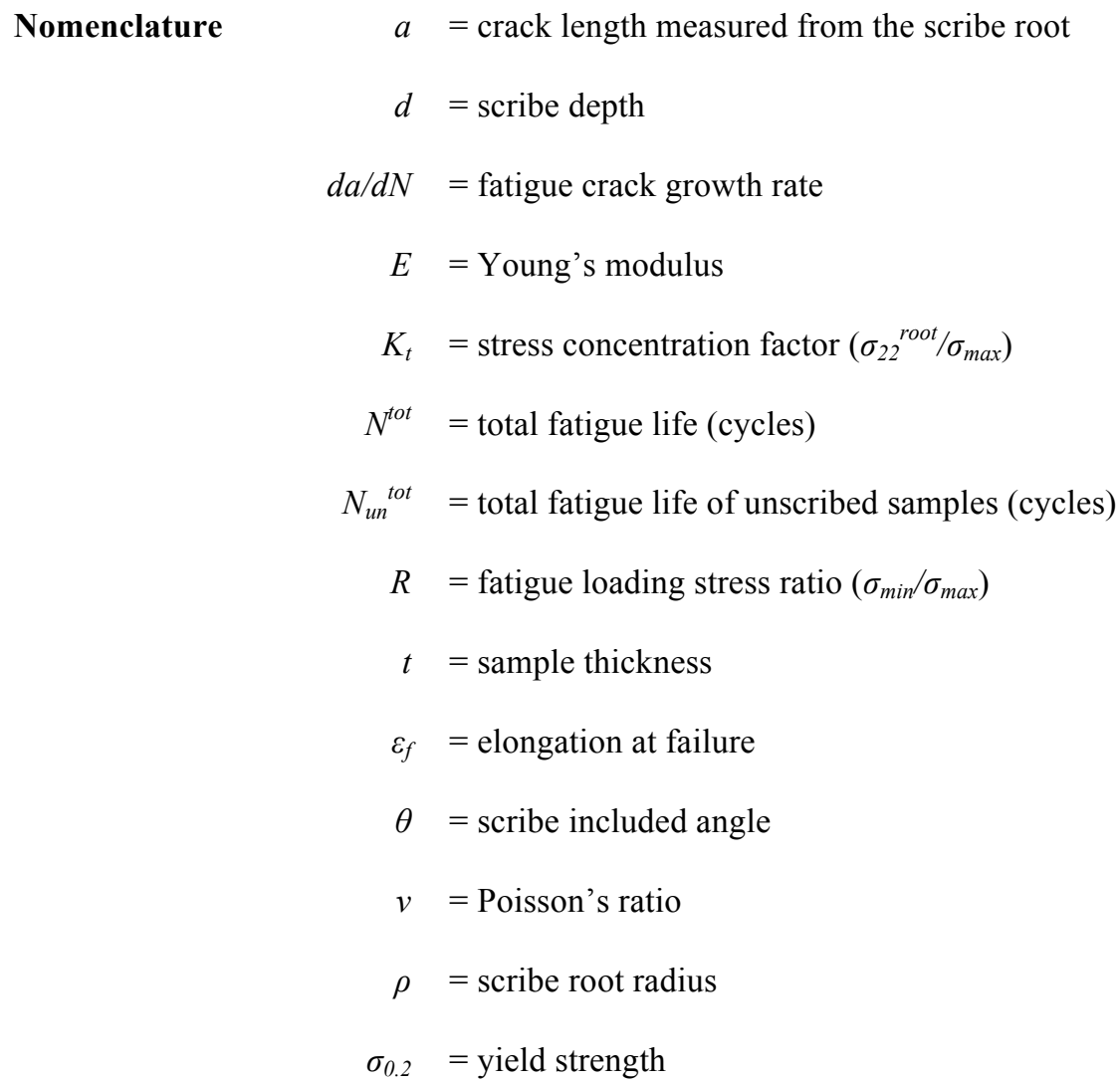




$$
\begin{aligned}
\sigma_{22}{ }^{\text {root }} & =\text { longitudinal stress at the scribe root } \\
\sigma_{\max } & =\text { nominal maximum fatigue stress at gauge section } \\
\sigma_{\min } & =\text { nominal minimum fatigue stress at gauge section } \\
\sigma_{U T S} & =\text { tensile strength }
\end{aligned}
$$

\section{Introduction}

Aircraft structures, except for landing gear and engines, are designed following the damage tolerance approach. Catastrophic failures are avoided by designing structures capable of tolerating defects caused by fatigue, corrosion or accidental impacts, until they can be detected and repaired ${ }^{1}$. However maintenance operations, if improperly performed, can cause accidental damage. Inappropriate tools or accidental impacts can damage aircraft and initiate widespread fatigue cracks less than a millimetre deep, making structures unable to meet damage tolerance requirements ${ }^{1}$.

Interest in maintenance induced damage was recently revived by the discovery of so called scribe marks at fuselage joints. Scribe marks are multiple scratches introduced on the fuselage skin along longitudinal and circumferential joints by the use of sharp tools during sealant removal process prior repainting ${ }^{2-5}$. Scribe marks can be metres long and widespread along every fuselage longitudinal and circumferential joint. While scribes have high variability in length and depth their usual cross section shows a rounded V-shape ${ }^{5}$. Scribe marks, no deeper than 200-300 $\mu \mathrm{m}$, located in highly stressed regions where the joint secondary bending is maximum, are capable of simultaneously initiating multiple small cracks along their roots which coalesce forming a wide crack propagating through the panel thickness ${ }^{5}$. Cracks propagating from scribes are difficult to detect during conventional inspections and when they become visible, after few thousand flights, the damage can be so extensive as to render aircraft beyond economic repair ${ }^{2}$.

If the scratch is regarded as a propagating crack, fracture mechanics can be used to calculate the life to failure ${ }^{6}$, but this approach is very conservative as it neglects fatigue cycles to create the crack. The interaction and coalescence of multiple small cracks together with short crack behaviour ${ }^{7-13}$ invalidates the use of conventional analysis for cracks nucleated from scribe marks before they become through thickness cracks. A new analysis method is therefore required, in the frame of damage tolerance philosophy to predict residual service life of scribed structure and define additional inspection and repair programs.

Fatigue crack development from mechanically induced scratches is a notch fatigue problem, where the stress concentrators are several centimetres long but a few tens of microns deep. The two different scales of length and depth, place long superficial scratches in an intermediate position between conventional engineering notches, several millimetres in size ${ }^{14-19}$, and small defects the size of the material characteristic microstructural lengths ${ }^{20-22}$. Together 
with the stress concentration caused by the scratch geometry, plastic deformation resulting from the scribing process inevitably causes residual stresses and material hardening at the notch root, in turn affecting fatigue crack nucleation and early propagation ${ }^{23}$.

Despite their widespread occurrence mechanically produced scratches have received little attention from fatigue workers. According to traditional fatigue life prediction methods based on notch sensitivity factor ${ }^{24,25}$, many materials are considered insensitive to scratches on components surfaces. More recently, experimental evidence showed that the presence of mechanically machined scratches had significant impact on fatigue life of aluminium ${ }^{26-29}$ and steel $^{30}$ components.

Previous investigations on fatigue behaviour of scratched components fall short of providing a detailed explanation of mechanisms involved in crack development from scratches. This research aims to investigate fatigue crack initiation and growth from mechanically machined scratches in clad and unclad 2024-T351 aluminium alloy sheets. The main objective is to characterise the effect of mechanical defects, such as surface scratches, on fatigue life of aluminium samples, providing a background to predict residual service life of aeronautical structures containing scribe marks. The influence of scratch geometry on fatigue cracks developing from scratches was isolated from the effects of plasticity and residual stress induced by the scribing process. A detailed analysis of the impact of plasticity and residual stress introduced by the scribing process on fatigue performance of scratched components can be found in ${ }^{31}$. Fatigue tests were conducted on both clad and unclad 2024-T351 aluminium samples. After testing fracture surfaces were examined in the SEM to characterise fracture morphology and to determine crack growth rates from striation spacing measurements. Stress fields and plastic zones at the scratch root were analysed using elastic-plastic finite element models to assess the local stress concentration effect on crack nucleation and early propagation. Experimental and finite element results were used to develop a model for predicting fatigue life of scribed structures and the scratch sensitivity of aluminium structures. FE analyses and the prediction model development are described in Part II of this paper.

\section{Experimental procedures}

\subsection{Material and experiment preparation}

The material studied was the aluminium-copper alloy 2024-T351 of which fuselage panels and joints of the majority of civil aircraft in service are made. Table 1 shows its specified chemical composition. The material was supplied as 2 $\mathrm{mm}$ thick rolled sheet clad panels in T351 temper condition ${ }^{33}$. Unclad 2024-T351 aluminium alloy, was produced by stripping the cladding using chemical milling. That process reduced the thickness to nearly $1.67 \mathrm{~mm}$. Metallographic 
examination of clad and unclad materials showed a pancake shape grain structure typical of rolled sheets with grains elongated along the rolling direction L. Grains were approximately 150-200 $\mu \mathrm{m}$ long along rolling direction L, 80-100 $\mu \mathrm{m}$ on transverse direction $\mathrm{T}$ and $20 \mu \mathrm{m}$ in the thickness direction $\mathrm{S}^{34}$. No grain structure was visible inside the pure aluminium clad layer. An average clad depth of $70-80 \mu \mathrm{m}$, that is around 3.5\% of the whole thickness, was measured on clad 2024-T351 aluminium panels using optical microscope $\mathrm{e}^{34}$.

Table 1 Specified chemical composition of Al 2024-T351 (wt $\%)^{32}$.

Fig. 1 Sample geometries for fatigue testing under tension (a) and 4 point bending (b) (dimensions in mm).

Table 2 Mechanical properties of 2424 sheet in the transverse direction LT.

Cracks developed from scribe marks at fuselage joints under the combination of fatigue tensile load and secondary bending caused by the joint eccentricity ${ }^{5}$. The effects of pure tension and pure bending loading on crack development from scribes were examined separately. were machined from clad and unclad 2024-T351 sheets to The geometries of tension and bending samples is shown in Fig. 1. A dogbone specimen with continuous radius between ends was chosen for pure tension (Fig. 1a) while a simple rectangular sample (Fig. 1b) was used to perform 4 point bend tests. A scribe was cut across the entire gauge section of the samples perpendicular to the load direction (Fig. 1). The gauge section width was $80 \mathrm{~mm}$ to accommodate long scratches representative of service scribes. Samples were machined with the rolling direction parallel to the scratch line (Fig. 1), consistent with the material orientation in longitudinal fuselage joints $^{34}$. Tensile and bending loads were therefore applied along the LT, transverse direction. Table 2 lists the mechanical properties of clad and unclad alloys measured along this direction.

Scribe section and depth in the test samples had to be regular and controllable. Micro notches of rounded V section, with depth $(d)$ between 25 and $185 \mu \mathrm{m}$, were cut across the entire gauge width in bending and tension specimens (Fig. 1) using a diamond tipped tool mounted on a precision planing machine ${ }^{34}$. Three different cross sections, characterised by root radii $(\rho)$ of 5,25 and $50 \mu \mathrm{m}$, were machined, while the included angle $(\theta)$ of the $\mathrm{V}$ was constant at $\theta=60^{\circ}$. Scribes were produced using cutting rather than scratching process which is more akin to ploughing, in order to minimise introduction of plasticity and residual stress around the scribe. These local changes would affect crack development at the scribe root and had to be minimised to investigate the relation between the scribe geometry and fatigue life. The process produced rounded V-sections tens of microns deep with regular and controllable cross sections. Two examples of the cross sections produced are shown in Fig. 2. After scribing all samples had their depth measured 
optically and selected specimens had the notch shape examined along the entire gauge length by a scanning confocal microscope $\mathrm{e}^{34}$. Depth was kept within $6 \%$ of its nominal value across the $80 \mathrm{~mm}$ width while maximum percentage errors from nominal root radius and open angle were respectively $8 \%$ and $2 \%$. Synchrotron X-ray diffraction and nanoindentation measurements on selected scribes, showed negligible levels of tensile residual stresses and work hardening in the material around them ${ }^{23}$. Such measurements, together with the absence of material piling up at the scribe flanks (Fig. 2), demonstrates the pure cutting nature of the scribing procedure.

Fig. 2 Cross section shape of diamond tool machined scribes: $100 \mu \mathrm{m}$ deep $5 \mu \mathrm{m}$ root radius scribe (a), $100 \mu \mathrm{m}$ deep 50 $\mu \mathrm{m}$ root radius scribe (b).

\subsection{Fatigue testing}

Tension and 4 point bend samples were tested under constant amplitude cyclic load control with $R=0.1$ and maximum stress of $\sigma_{\max }=200 \mathrm{MPa}$ at the gauge section. The $\sigma_{\max }$ of $200 \mathrm{MPa}$ was selected as on unscribed samples it gave fatigue lives comparable to those of tested panels and joint coupons cut from retired medium-range aircraft (2$3 \cdot 10^{5}$ flights). In the case of 4 point bend loading the nominal stress condition referred to the surface stress at the gauge section. The nominal stress was defined as the stress which the gauge section would withstand, according to the San Venant's beam theory, if the material was linear elastic ${ }^{34}$.

Tensile tests were performed at $10 \mathrm{~Hz}$ at 20 in lab air. A total of 49 tensile specimens were tested with a combination of five different scribe depths $(25 \mu \mathrm{m}, 50 \mu \mathrm{m}, 100 \mu \mathrm{m}, 150 \mu \mathrm{m}, 185 \mu \mathrm{m})$ and three root radii $(5 \mu \mathrm{m}, 25$ $\mu \mathrm{m}, 50 \mu \mathrm{m})$ on clad and unclad samples. Each test was duplicated apart from scribes $25 \mu \mathrm{m}$ deep or with $25 \mu \mathrm{m}$ root radii where only a single specimen was tested ${ }^{34} .4$ point bending tests were carried out under the same conditions but at a test frequency of $1 \mathrm{~Hz}$ because of the large displacements incurred under the loads required to achieve $200 \mathrm{MPa}$ surface stress. Fig. 3 shows a sketch of the rig used for 4 point bending tests. Sample anticlastic curvature was inhibited by rig configuration to simulate the constraint exerted by rivets on fuselage jointed panels. 26 clad and unclad bending specimens containing scratches with root radii of $5 \mu \mathrm{m}$ and $50 \mu \mathrm{m}$ and three depths $(50 \mu \mathrm{m} 100 \mu \mathrm{m}$ and $185 \mu \mathrm{m})$ were tested, duplicating each test. Pristine specimens were tested in tension and bending to have reference lives for comparison $^{34}$. In all tests the failure criterion was complete sample fracture.

Fig. 3 sketch of 4 point bending rig (dimensions in $\mathrm{mm}$ ). 


\subsection{Fractography and crack growth measurements}

Fracture surface observation was carried out post testing using a high resolution FEG SEM. Quantitative measurements of initiation sites and final crack size and shape were performed.

Local crack growth rate data were obtained via striation counting assuming, that striations are marks left every fatigue cycle ${ }^{36}$. Striation spacing was measured at 10-20 locations on cracks at a range of depths along a line intersecting the final crack front at its deepest point ${ }^{34}$. Pictures were taken at each spot, with magnification up to 130000X, and a total of 3 striation spacing measurements performed for each crack depth. A total of 8 tension samples, 4 clad and 4 unclad, containing respectively $185 \mu \mathrm{m}$ and $50 \mu \mathrm{m}$ deep scratches with $50 \mu \mathrm{m}$ and $5 \mu \mathrm{m}$ root radius were analysed. Only 4 bending specimens had their striation spacing measured: a clad and an unclad $185 \mu \mathrm{m}$ deep $5 \mu \mathrm{m}$ root radius scribed sample, a $185 \mu \mathrm{m}$ deep $50 \mu \mathrm{m}$ root radius and a $50 \mu \mathrm{m}$ deep $5 \mu \mathrm{m}$ root radius scribed unclad specimens.

\section{Results}

\subsection{Fatigue test results}

Fig. $4 \mathrm{a}$ and $\mathrm{b}$ show tension and bending fatigue lives plotted against scribe depth and root radius for clad and unclad specimens. Fatigue lives of pristine samples are plotted with zero notch depth. All scribed samples failed from fatigue cracks initiated at the scribe root apart from an unclad tension sample with a $25 \mu \mathrm{m}$ deep, $50 \mu \mathrm{m}$ root radius scribe that after nearly $8 \cdot 10^{5}$ cycles had the test stopped. Moreover clad specimens tested in bending containing $50 \mu \mathrm{m}$ deep, 50 $\mu \mathrm{m}$ root radius scribes failed at locations other than the scribe line.

Pristine samples failed via fatigue cracks located at the minimum gauge section. Specimens containing $25 \mu \mathrm{m}$ deep scribes with $25 \mu \mathrm{m}$ and $50 \mu \mathrm{m}$ root radii had lives comparable to pristine samples. Fig. 4 shows that introduction of scribes caused reduced variability in fatigue lives compared to that observed for pristine samples under the same nominal stress condition ${ }^{37,38}$. Samples tested in bending showed a larger variability compared with tension tests. Fatigue life decreased with increasing scribe depth for a given root radius and reducing the root radius with a fixed depth had the same effect (Fig. 4). Scribes reduced the fatigue life under tensile load by up to $97.7 \%$ for the deepest and sharpest scribes (185 $\mu \mathrm{m}$ deep $5 \mu \mathrm{m}$ root radius scribe). Even shallow scribes such as $25 \mu \mathrm{m}$ deep and $25 \mu \mathrm{m}$ root radius resulted in a 30\% life reduction for clad tension samples (Fig. 4a). Fatigue lives of bending samples were on average a factor of 3 longer than the corresponding tension ones (Fig. 4b). Clad samples showed fatigue lives on average $40-50 \%$ longer than unclad specimens. 
Fig. 4 Sample fatigue life as function of scratch depth and root radius under tension (a) and 4 point bending (b).

\subsection{Fractography observations}

Multiple fatigue cracks nucleated at notch roots along the entire scribe length, growing through thickness in all samples (Fig. 5a). Table 3 lists the fracture front morphology of tension clad samples. The number and linear density of crack nucleation sites along scribe roots increased for deeper notches with smaller root radii (Table 3). Multiple cracks coalesced during propagation, forming fracture surfaces with different shapes. Scribes deeper than $50 \mu \mathrm{m}$ under tensile loading developed a single elongated fracture front covering the entire sample width whereas scribes shallower than 50 $\mu \mathrm{m}$ showed fracture surfaces made of multiple thumbnail and corner cracks (Table 3 and Fig. 5c). On samples with 25 $\mu \mathrm{m}$ and $50 \mu \mathrm{m}$ root radii, the elongated crack fronts showed arrays of parallel coalescence steps (coalesced front), suggesting that the fracture front had been made of cracks growing on different planes prior to coalescence (Fig. $5 \mathrm{~b}$ ). Cladding seemed not to influence the fracture morphology as clad and unclad samples containing the same scribes showed similar crack morphology. Under bending loading, the transition between multiple crack and elongated fracture fronts occurred at scribes $100 \mu \mathrm{m}$ deep $^{34}$. In specimens showing multiple crack fronts the crack causing sample failure was at the specimen edge which was also the starting location of unstable propagation in single crack fronts.

Table 3 Fracture front morphology of tension clad samples.

Fig. 5 Fracture surface morphology: thumbnail crack at the root of $25 \mu \mathrm{m}$ deep $50 \mu \mathrm{m}$ root radius scribe in tension clad specimen (a), elongated crack front with coalescence steps at the root of $185 \mu \mathrm{m}$ deep $50 \mu \mathrm{m}$ root radius scribe in a tension clad sample (b), multiple thumbnail crack fronts at the root of $50 \mu \mathrm{m}$ deep $50 \mu \mathrm{m}$ root radius scribe in a tension unclad sample (c).

Fatigue cracks generally nucleated in tension and bending from intermetallic particles, voids and superficial damages at the scribe root. Fig. 6a shows a surface crack nucleated from intermetallic particles at the $50 \mu \mathrm{m}$ root radius of a $50 \mu \mathrm{m}$ deep scribe in tension unclad sample. Nucleation occurred slightly earlier at sample edges, where the deepest crack fronts were observed ${ }^{34}$. At roots of small scribes completely embedded into the clad layer there were no substantial changes from the nucleation mechanisms, taking place in the 2024-T351 aluminium alloy substrate. However nucleation from intermetallic particles was not observed from sites inside the clad layer, as consequence of its low content of inclusions and intermetallic particles ${ }^{39}$. 
Where crack nucleation took place, an initial uneven region of fracture a few microns deep, characterised by microcliffs separated by regions with irregular appearance was observed (Fig. $6 \mathrm{~b}$ and c). Fracture surfaces, produced by early crack growth in 2024-T351, showed a jagged aspect with arrays of lamellar features forming micro steps parallel to the local growth direction (Fig. 6a and b). The lamellae were formed by crack growth along different planes of the same slip system inside a grain and changed their orientation and planar slope at grain boundaries because of the tilt angle between favoured slip systems in adjacent grains ${ }^{40}$. Different crack propagation plane orientations in diverse grains are pointed out by variations of surface brightness in Fig. 6a and b. On the whole cracks remained perpendicular to the loading direction but locally grew along crystallographic planes (stage I-like ${ }^{41}$ ). If scribes were completely embedded into cladding, initial crack growth was into pure aluminium. Generally propagation through cladding of small thumbnail cracks was characterised by a geometric structure composed of regular facets (Fig. 6c), typical of crystallographic stage I fatigue crack growth ${ }^{42}$. The growth plane orientation changed at grain boundaries. As soon as the crack approached the substrate the facets were replaced by the 'feathery' corrugated features, as those typical of crystallographic stage I growth in 2024-T351 aluminium alloy (Fig. 6c). Crack growth in the substrate was recognisable by the development of the peculiar lamellar arrays (Fig. 6c). For large thumbnail or elongated through sample width cracks, growth into cladding resulted in a structure insensitive amorphous fracture surface, perpendicular to the loading direction ${ }^{34}$. Propagation returned to microstructure sensitive once the crack grew into the substrate.

Early crack growth from scribe roots showed a strong microstructure sensitivity. Despite different scribe geometries and presence or absence of cladding, transgranular stage II growth (Fig. 6d) developed when cracks reached depths from the sample surface of 180-235 $\mu \mathrm{m}$ under tensile and 240-285 $\mu \mathrm{m}$, under bending loads ${ }^{34}$. Stage II crack growth was characterised by multiple raised plateaus, where fatigue striations were detected (Fig. 6d). All samples failed showing a final ductile fracture characterised by void coalescence (Fig. 5 and Fig. 6).

Fig. 6 Fatigue crack development in scribed samples: thumbnail crack nucleation from inclusion and early propagation at the root of $50 \mu \mathrm{m}$ deep $50 \mu \mathrm{m}$ root radius scribe in unclad tension sample (a), microstructure sensitive crack growth in $50 \mu \mathrm{m}$ deep $5 \mu \mathrm{m}$ root radius scribed unclad tension specimen (b), crack growth through cladding in $25 \mu \mathrm{m}$ deep 5 $\mu \mathrm{m}$ root radius scribed clad sample (c), crack growth through different stages in $185 \mu \mathrm{m}$ deep $5 \mu \mathrm{m}$ root radius scribed unclad tension specimen (d).

\subsection{Crack growth rate measurements using striation counting}

Striation spacing measurements were carried out from the scribe root up the crack depth where void coalescence occupied nearly $50 \%$ of the fracture surface ${ }^{34}$. No striations were detected in the region of microstructure sensitive 
propagation. Fig. 7 shows crack growth rates, deduced from striation spacings of all the tension and bending samples examined, plotted against the distance from the scribed surface $a+d$ normalised by specimen thickness $t$. The normalised depth $(a+d) / t$ takes into account the sample finite thickness effect on crack propagation rate. Specimens are indicated in Fig. 7 using a nomenclature where the first letter specifies the loading condition ( $\mathrm{T}=$ tension, $\mathrm{B}=\mathrm{bending})$, the second the material ( $\mathrm{U}=$ unclad, $\mathrm{C}=\mathrm{clad}$ ) and the following numbers define respectively scribe depth and root radius in $\mu \mathrm{m}^{34}$. Measured growth rates ranged from a minimum value of $0.032 \mu \mathrm{m} / \mathrm{cycle}$ up to a maximum of $0.680 \mu \mathrm{m} / \mathrm{cycle}$. Crack growth rates of tension specimens were well correlated by normalised depth for all scribe geometries, cladding state and crack front shape (Fig. 7). Growth rates under tensile load were an exponential function of increasing normalised crack depth.

Under bending load growth rates were approximated by a third degree polynomial function of normalised crack depth following an S-shaped trend in all samples (Fig. 7). For normalised depth smaller than 1.5, cracks propagated at comparable rates under tensile and bending loads. As soon as cracks became bigger, bending growth rate became up to $60 \%$ slower than the tension one. For bending loads normalised crack depth did not unify growth rates in different scribed samples as accurately as for tensile loading. In particular propagation rates from $50 \mu \mathrm{m}$ deep, $5 \mu \mathrm{m}$ root radius scribed sample were still smaller than those from other bending samples even after considering the finite thickness effect (Fig. 7). The different crack fronts composed of multiple cracks rather than the elongated ones exhibited by the other bending samples was thought to be the main cause of growth rate reduction.

Fig. 7 Experimental crack growth rate in tension and bending samples.

\section{Discussion}

\subsection{Effect of scribes on fatigue life}

Stress concentration factors, $K_{t}$, for each scribe geometry and loading mode were calculated by performing twodimensional linear elastic finite element analysis. Details of the calculation are given in ${ }^{43}$. Table 4 lists gross elastic $K_{t}$ values of each scribe geometries under tensile and bending loads. No distinction was made between concentration factors on clad and unclad samples as the elastic properties of substrate and cladding materials were identical and the small variation caused by the different sample thickness was neglected ${ }^{43}$. Because of the small size of scribes compared to the sample thickness $(d / t<1 / 10), K_{t}$ was mainly regulated by the notch aspect ratio $\rho / d$ as for V-notches in semiinfinite plates ${ }^{44}$. 
Table 4 Stress concentration factors of scribes under tensile and bending load.

Scribe fatigue lives normalised with respect to lives of unscribed specimens, $N^{\text {tot }} / N^{\text {tot }}$ un are plotted against stress concentration factors in Fig. 8a to isolate the scribe geometry effect on fatigue. Irrespective of loading mode and cladding status, normalised fatigue lives of samples with the same root radius all lie on the same curve. There are separate data trends for different root radii, demonstrating the well-established inability of elastic $K_{t}$ alone to characterise the effect of notches on fatigue life ${ }^{24,25}$.

The exception to the trend is for $25 \mu \mathrm{m}$ deep, $5 \mu \mathrm{m}$ root radius scribes $\left(K_{t}=5.88\right)$, which showed a smaller life reduction for clad than for unclad tension samples (Fig. 8a). The effect of scribes on fatigue life is therefore independent of loading mode and is reduced by cladding only for scribes with their root embedded within the soft layer. This smaller life reduction was thought to be caused by notch root blunting in the soft aluminium. Blunting was believed to be hampered by the constraint exerted by the nearby harder substrate for $50 \mu \mathrm{m}$ deep scratches, as their normalised lives were the same in both clad and unclad samples. $50 \mu \mathrm{m}$ deep, $50 \mu \mathrm{m}$ root radius scribes $\left(K_{t}=2.96\right)$ generated fatigue fracture in unclad bending specimens but not in clad ones (Fig. 4 and Fig. 8a). Kt values $\leq 2.43$ in tension and $\leq 2.96$ in bending had no effect on fatigue life and represent a threshhold condition. Scribes with Kt less than this (Fig. 4) were found to be as deep as the size of the inclusion clusters $(23-60 \mu \mathrm{m})$ which nucleated propagating fatigue cracks in pristine samples $^{34}$

Cladding and bending loading modes both shifted sample fatigue lives to greater number of cycles compared to the lives of corresponding tension specimens (Fig. 4). For a given surface stress, a longer crack nucleation period is commonly observed in bending fatigue and is generally ascribed to the smaller volume of highly stressed material in bending stress gradient ${ }^{45}$. This cause seems unlikely in the current tests as the root stress volume in tension and bending will not be significantly different. An alternative explanation for the increased bending lives is the crack propagation from scribes which had growth rates up to $85 \%$ slower than in tension (Fig. 7). As well as increasing the fatigue life of scribed samples, cladding increased the life of pristine specimens by nearly $43 \%$ (Fig. 4). This behaviour was inconsistent with data reported in prior literature where the clad layer is reported to have a large detrimental effect on S$\mathrm{N}$ curve of aluminium alloys. This was interpreted as being due to the plastic shake down of the soft pure aluminium which promoted crack nucleation ${ }^{46,47}$. In the current work work fatigue life of clad specimens was thought to be regulated not by crack nucleation but by the increased cycles required for a crack to penetrate into the substrate material $^{47}$. The longer life of unscribed clad samples was ascribed to fatigue crack nucleation from subsurface inclusion clusters, increasing the initiation life $\mathrm{e}^{34}$. The effect of cladding and bending load on local scribe stress fields and its implications in initiation and propagation lives are discussed in Part II of this paper. 
Fig. 8 Effect of the scribe geometry on total fatigue life of aluminium samples (a) and on nucleation site density and fracture morphology of clad specimens (b).

\subsection{Crack development from scribes}

Scribes reduced specimen fatigue lives via initiation of multiple fatigue cracks at their roots where raised stress caused dislocation motion and plasticity, which in turn are responsible for crack formation. Similar multiple nucleation processes have been observed in other investigations on scratches ${ }^{5,26}$. The scribe root will intersect different grains of different orientations and their variability in orientation will give a range of values of critical resolved shear stress for slip, determined by the value of the Schmid factor in each grain. Crack nucleation will also be promoted by the presence of inclusions of a range of diameters within the grains and their location with respect to the notch root. For a given scribe geometry cracks will initiate first and grow fastest in stage I single slip growth in grains which have the largest inclusions nearest the notch root and the largest value of the Schmid factor (0.5).

Scribe geometry regulated the number of crack nucleation points per unit length of scribe root, (Table 3). Fig. 8b shows the linear density of nucleation sites as a function of $\mathrm{Kt}$ in clad samples. Specimen fracture front morphology is indicated as well in Fig. 8b. Unclad samples showed a similar trend to that in Fig. 8b. The linear density of crack nucleation points increased with Kt. Only scribes with $25 \mu \mathrm{m}$ depth in tension and $50 \mu \mathrm{m}$ depth in bending deep, with 5 $\mu \mathrm{m}$ root radius deviated from this trend (Fig. 8b).

For scribes with $K_{t}<4.08$, nucleation points had a density of $<2.631 / \mathrm{mm}$ (Fig. 8b). Crack nuclei were more than $380 \mu \mathrm{m}$ apart on average, generating fracture fronts made by multiple superficial flaws. If $4.08 \leq K_{t} \leq 8.07$, resistance to dislocation motion was overcome over an increased number of initiation sites generating a nucleation site density from $2.631 / \mathrm{mm}$ to $7.541 / \mathrm{mm}$ (Fig. 8 b). Crack nuclei were $130-180 \mu \mathrm{m}$ apart and coalesced in the early stage of their propagation to form a single elongated coalesced fracture front as for $185 \mu \mathrm{m}$ deep $50 \mu \mathrm{m}$ root radius scribes. Coalescence steps were mainly developed from 25 and $50 \mu \mathrm{m}$ root radii scribes, where larger radii promoted crack nucleation and early growth on parallel offset planes. For sharp scribes with $K_{t}>8.07$, as $185 \mu \mathrm{m}$ deep $5 \mu \mathrm{m}$ root radius ones (Fig. 8b), a nucleation site was activated on average every 100-130 $\mu \mathrm{m}$ along the scribe root (linear density $>7.54$ $1 / \mathrm{mm}$ ). The nucleation process was so spread that a crack few microns deep but lengthened along the entire scribe length was thought to develop at the scribe root.

There was a correlation between the fracture front morphology and the fatigue life of scribed samples as shown in Fig. 8a. Scribes producing multiple crack fronts had reduced fatigue lives as small as $14 \%$ of those of pristine samples. Smaller lives were reached only by developing elongated crack front with or without coalescence steps (Fig. 8a). At 
normalised fatigue lives around $N^{\text {tot }} / N^{\text {tot }}{ }_{u n}=14 \%$ bending samples developed multiple crack fronts while tension ones generated single fracture fronts.

Early crack growth from scribe marks was sensitive to material grain structure in both cladding and substrate. Crack propagation in cladding showed regular facets typical of crystallographic stage I growth (Fig. 6c) or amorphous structure-insensitive fracture surfaces depending on the crack size. A possible explanation for such different behaviour could be imputed to different constraints exerted along crack fronts ${ }^{48}$ or to a diverse crack growth rate. The microstructural nature of early crack propagation from scribes was consistent with the formation of multiple small cracks at the scribe root which afterwards coalesced to form larger fracture fronts. In fact the congruence constraint exerted on a crack encompassing many grains promotes the development of structure insensitive stage-II growth ${ }^{48}$. The transition to stage II growth in scribed samples seemed to be regulated by the crack tip plastic zone rather than by the notch plastic zone as the transition crack depth was independent of scribe geometry being regulated only by loading condition.

Fig. 9 Comparison between measured growth rates of cracks from scribe marks and calculated rates for single edge notch cracks under tensile and bending loads as function of normalised distance from the sample surface.

Ductile striations were clearly visible only when transgranular stage II growth developed, that is $50-100 \mu \mathrm{m}$ and 100-190 $\mu \mathrm{m}$ from the scribe root under tensile and bending loads respectively. Scribe geometry and cladding did not affect crack growth data as growth rates of different samples had a single trend line when plotted against normalised crack depth $(a+d) / t$ (Fig. 7). The effect of the thicker clad samples and of notch depth was to modify the sample net ligament length and the consequent finite thickness influence exerted on cracks. Fig. 9 shows a comparison between crack growth rates measured by striation counting and those calculated for single edge notch cracks using long crack growth curve $\mathrm{e}^{49}$ on tension and bending samples. The long crack shape was selected as two-dimensional through-width edge cracks. These have the highest growth rate for a given crack depth. Cracks nucleated from scribes showed typical short crack behaviour, growing up to 10 times faster than long cracks with the same normalised depth. Measured growth rates merged with long crack data for depths close to the critical value for unstable fracture Fig. 9. Bending samples showed striation growth rates smaller than long crack ones for cracks approaching the sample edge. Such anomalous behaviour was thought to be caused by the development of a plastic hinge in the sample net ligament under 4 point bending load, which reduces the crack driving force ${ }^{34}$.

\subsection{Diamond tool scribes vs. simulated in-service scribes}


Diamond cut scribes were not representative of in-service scratches, produced by sealant removal from fuselage joints. Even with similar geometry, in-service scratches produced by ploughing had considerable plasticity and residual stress fields in and around the notch root, altering the fatigue crack development ${ }^{31,52,53}$.

The effect on fatigue life of scribes similar to in-service ones was analysed to assess the relevance of fatigue data generated on diamond cut scribes to aircraft service. In related work, simulated in-service scribes were introduced into dogbone samples (Fig. 1a) using plastic scrapers, steel knife blades, aluminium alloy blades and high strength steel tools $^{31,52,53}$. It was reported that plastic scrapers, recommended for sealant removal, were not able to scratch the surface of clad and unclad aluminium alloy samples ${ }^{52}$. Samples were subsequently fatigued under the same conditions as the diamond cut scribes ${ }^{31,52,53}$. Fig. 10 shows fatigue lives of simulated service scribes and diamond cut ones, plotted against scribe elastic $K_{t}$. Runout samples are indicated by arrows, open symbols specify specimens failing at their edge rather than at the scribe root. Fatigue test data reported in figures 4 and 8 were compared to data from Morency ${ }^{51}$, testing $5 \mu \mathrm{m}$ root radius scribes machined by a damaged diamond tool and Tizard $^{31}$, who fatigued samples scribed by an high strength steel tool (Fig. 10a). For clad samples, fatigue data from simulated service scribes, obtained by Irving et al. $^{50}$, using an high speed steel tool, Walmsley ${ }^{52}$, by plastic and aluminium scrapers, Jozelich ${ }^{53}$, using aluminium tools and Stanley knifes, and Morency ${ }^{51}$ are used for comparison (Fig. 10b).

Fig. 10 Effect of diamond tool and like in-service scribes on fatigue life of unclad (a) and clad (b) samples.

Generally simulated service scribes were less damaging for clad and unclad 2024-T351 aluminium alloy sheets than scribes cut by diamond tools. All the fatigue life data of samples with simulated service scribes, including also scribes machined by the damaged diamond tool, were greater than those with diamond cut specimens (Fig. 10). Simulated scribes were more averse than diamond tool ones to initiate fatigue cracks. Simulated scribes with $K_{t} \leq 6$ for unclad ${ }^{31}$ and $K_{t} \leq 4-5.5$ for clad samples ${ }^{46,48}$ had the same fatigue lives as pristine samples (Fig. 10).

Nanoindentation measurements on simulated service scribes showed increased hardness around their profiles compared to diamond scribes (Fig. 11) and also the existence of compressive residual stresses close to the material yield strength at the notch roots ${ }^{31}$. The inelastic deformation on simulated scribing gave rise to local hardening (Fig. 11) and plasticity-induced compressive residual stresses. These processes are largely absent in diamond cut scribes.

The increase in material hardness and the compressive residual stresses are believed to be responsible for the improved fatigue performances of simulated service scribes ${ }^{31}$. Crack initiation and early propagation at the scribe root, will be retarded making the total lives of service scribed samples longer than those of diamond tool ones ${ }^{31}$. A fatigue life prediction method based on the experimental data of diamond tool scribed samples will give conservative lives when applied to scratches found on in-service aircraft. 
Fig. 11 Material hardness along the centreline of diamond cut and simulated service scribes measured by nanoindentation ${ }^{31}$.

\section{Conclusions}

- Diamond cutting tools with root radii of 5, 25 and $50 \mu \mathrm{m}$ and a face angle of $60^{\circ}$ can be used to produce cut scribes in the surface of sheet samples of 2024-T351 of depth between 25 and $180 \mu \mathrm{m}$ with the above root radii and with minimal associated plasticity.

- Tensile and bending fatigue testing has been performed at $200 \mathrm{MPa}, \mathrm{R}=0.1$ on 2024-T351 aluminium samples clad and unclad containing diamond cut scribes. Scribes with elastic stress concentration factors $K_{t} \geq 2.43$ in tension and $K_{t} \geq 2.96$ in bending reduced fatigue life by up to $97.8 \%$ due to multiple crack nucleation at their roots.

- Scribes with stress concentrations less than $\mathrm{Kt}=2.43$ did not initiate fatigue cracks and represent a threshold condition.

- Clad samples showed nearly 50\% increased fatigue life compared to unclad specimens with the same scribe geometry. Scribed samples, fatigued under pure bending load, showed the same trend as under tension, but produced lives on average 3 times longer than corresponding tension specimens due to slower crack propagation.

- Post-test fractogaphy revealed that multiple crack initiation occurred from scribes usually from intermetallic particles, defects or favourably oriented grains along the root. The number of crack nucleation sites per unit length of scribe root increased with $K_{t}$. For $K_{t}>8.07$, the nucleation site density $>7.541 / \mathrm{mm}$ promoted the development of multiple short cracks which coalesced, during early propagation, forming a single crack along the whole sample width. Scribes with $K_{t}<4.08$, had a linear nucleated crack density $<2.631 / \mathrm{mm}$, generating fracture surfaces of multiple thumbnail and corner cracks. For $4.08 \leq K_{t} \leq 8.07$, tension and bending samples showed elongated or multiple crack fracture fronts depending on scribe depth and loading conditions.

- Early crack growth was strongly influenced by material microstructure, despite different notch geometry, cladding and load conditions. The transition between stage I-like and stage II growth seemed to be regulated by the crack tip plastic zone rather than by the notch plastic zone. Scribe geometry influenced only the microstructure sensitive stage I-like crack propagation.

- Crack growth rate was measured performing striation counting on fracture surfaces. Fatigue ductile striations were clearly visible when stage II growth developed (50-190 $\mu \mathrm{m}$ from the scribe root). Cracks propagation in bending 
was up to $60 \%$ lower than in tension. Cracks nucleated from scribes showed the typical short crack behaviour for the entire propagation stage, growing up to 10 times faster than long cracks with the same size and shape.

- A comparison of fatigue lives of samples with diamond scribes with samples containing simulated scribes showed that simulated service scribes were less effective in producing fatigue cracks. This is attributed to their greater plasticity and compressive residual stress. Fatigue life predictions of service scribes based on experimental data of diamond tool scribed samples are therefore conservative as the scribing process was most damaging.

\section{Acknowledgments}

This research activity was founded by Airbus. The support of Dr. Domenico Furfari From Airbus in providing the research group with samples as well of Mr. Ben Hopper from Cranfield University in scribing specimens is gratefully acknowledged.

\section{References}

1. Bristow, J. W. (1999) The meaning of life. Paper 24/1 CEAS forum on life extension-Aerospace technology opportunities, March 1999 Cambridge, UK pub RAES.

2. Fuselage Skin 'Scribe Mark' Damage on Boeing 737 Aircraft. FAA flight Standards Information Bulletin for Airworthiness-FSAW 03-10B, 20/11/2003.

3. Paint and sealant removal process. Airworthiness Notice No. B071, 3/11/2004.

4. FAA Airworthiness Directives No. FAA-2005-20918, 31/3/2006.

5. Das, G., Kosai, M., Miller, M. (2007) Development of a method for damage tolerance analysis for scribe marks adjacent to fuselage longitudinal and circumferential splices. In: International Committee on Aeronautical Fatigue (ICAF) meeting, Napoli, Italy, 14-18 May 2007.

6. Chang, J. B. (1981) Damage tolerance of metallic structures: analysis methods and applications. ASTM special technical publication 842. ASTM, Philadelphia.

7. Ritchie, R. O., Suresh, S. (1983) Mechanics and physics of the growth of small cracks. In: AGARD Conference Proceedings 328, 1983, pp. 1.1-1.14.

8. Schijve, J. (1984) The practical and theoretical significance of small cracks. An evaluation. In: Fatigue 84. University of Birmingham, UK, 1984, pp. 751-771. 
9. Miller, K. J. (1984) The initiation and growth rates of short fatigue cracks. In: Fundamentals of deformation and fracture: Eshelby memorial symposium (edited by Bilby, B. A., Miller, K. J., Willis, J. R.) Sheffield, 2-5 April 1984, Cambridge University Press: New York, 1985, p. 477-500.

10. Leis, B. N., Hopper, A. T., Ahmad, J., Broek, D., Kanninen, M. F. (1986) Critical review of the fatigue growth of short cracks. Eng. Fract. Mech., 23(5), 883-898.

11. Miller, K. J. (1987) The behaviour of short fatigue cracks and their initiation Part I-a review of two recent books. Fatigue Fract. Eng. Mater. Struct., 10(1), 75-91.

12. Miller, K. J. (1987) The behaviour of short fatigue cracks and their initiation Part II-a general summary. Fatigue Fract. Eng. Mater. Struct., 10(2), 93-113.

13. Ritchie, R. O., Peters, J. O. (2001) Small fatigue cracks: mechanics, mechanisms and engineering applications. Mater. Trans., 42(1), 58-67.

14. Foth, J., Marissen, R., Trautmann, K.-H., Nowach, H. (1986) Short crack phenomena in a high strength aluminium alloy and some analytical tools for their prediction. In: The behaviour of short fatigue cracks (edited by Miller, K. J., de los Rios, E. R.). EGF Pub. 1 Mechanical Engineering Publications: London, 1986, pp. 353-368.

15. Newman, J. C. Jr., Edwards, P. R. et al. (1988) Short-crack growth behaviour in an aluminium alloy-An AGARD cooperative test programme. AGARD report 732.

16. Edwards, P. R., Newman, J. C. Jr. et al. (1990) Short-crack growth behaviour in various aircraft materials. AGARD report 767.

17. Newman, J. C. Jr., Wu, X. R., Venneri, S. L., Li, C. G. (1994) Small-crack effects in high-strength aluminium alloy. NASA RP-1309.

18. Wu, X. R., Newman, J. C. Jr., Zhao, W., Swain, M. H., Ding, C. F., Phillips, E. P. (1998) Small-crack growth and fatigue life predictions for high-strength aluminium alloys: Part I-experimental and fracture mechanics analysis. Fatigue Fract. Eng. Mater. Struct., 21(11), 1289-1306.

19. Newman, J. C. Jr., Wu, X. R., Swain, M. H., Zhao, W., Phillips, E. P., Ding, C. F. (2000) Small-crack growth and fatigue life predictions for high-strength aluminium alloys. Part II: crack closure and fatigue analyses. Fatigue Fatigue Fract. Eng. Mater. Struct., 23(1), 59-72.

20. Murakami, Y., Endo, M. (1983) Quantitative evaluation of fatigue strength of metal containing various small defects or cracks. Eng. Fract. Mech., 17(1), 1-15.

21. Murakami, Y., Endo, M. (1980) Effect of small defects on fatigue strength of metals. Int. J. Fatigue, 2(1), 23-30. 
22. Murakami, Y., Endo, M. (1986) Effects of hardness and crack geometries on $\Delta \mathrm{K}_{\mathrm{th}}$ of small cracks emanating from small defects. In: The behaviour of short fatigue cracks (edited by Miller, K. J., de los Rios, E. R.). EGF Pub. 1 Mechanical Engineering Publications: London, pp. 275-293.

23. Khan, M. K., Fitzpatrick, M. E., Hainsworth, S. V., Edwards, L. (2009) Effect of tool profile and fatigue loading on the local hardness around scratches in clad and unclad aluminium alloy 2024. Mat. Sci. Eng. A, 527(1-2), 297304.

24. Neuber, H. (1946) Theory of notch stresses: principle for exact stress calculation. Edwards: Ann Arbor, MI.

25. Peterson, R. E. (1959) Notch sensitivity. In: Metal fatigue (edited by Sines, G., Waisman, J. L.). MacGraw-Hill: New York, 1959, pp. 293-306.

26. Nader, N. A. (1993) The effect of scratches on fatigue life and fatigue crack growth of Al 2024-T3 clad. Ph.D. thesis, Wichita State University, US.

27. Talia, M., Talia, J. E. (1997) Crack propagation modeling for surface generated scratches in Al 2024-T3 clad alloy. J. Mech. Behav. Mater., 8(2), 117-139.

28. Talia, M., Talia, J. E. (1997) The effects of scratches and shot peening on the high cycle fatigue crack growth of aluminium alloy 2024-T3. In: High Cycle Fatigue of Structural Materials. Indianapolis, Indiana, USA, 14-18 Sept 1997, pp. 409-426.

29. Inchekel, A., Talia, J. E. (1994) Effect of scratches on the fatigue behaviour of an Al-Li alloy. Fatigue Fract. Eng. Mater. Struct., 17-5, 501-507.

30. Everett, R. A. Jr., Newman, J. C. Jr., Phillips, E. P. (2002) The effect of Machining-like scratch on the fatigue life of 4340 steel. J. Am. Helicopter Soc., 47(3), 151-155.

31. Tizard, D. G. (2010) The influence of plasticity and residual stress in the fatigue performance of real world scribes in fuselage materials. M. Sc. thesis, Cranfield University, UK.

32. British Standard BS EN 573-3:2007. Aluminium and aluminium alloy - Chemical composition and form of wrought products - Part 3: Chemical composition and form of products, 2007.

33. British Standard BS EN 515:1993. Aluminium and aluminium alloy - Wrought products - Temper designations, 1993.

34. Cini, A. (2012) Scribe marks at fuselage joins: initiation and propagation of fatigue cracks from mechanical defects in aluminium alloys. Ph.D. thesis, Cranfield University, UK.

35. Airbus Material Specification AIMS 03-04-022, issue 4, October 2003.

36. Suresh, S. (2004) Fatigue of materials. $2^{\text {nd }}$ ed., Cambridge University Press: New York. 
37. Kermanidis, Al. Th., Petroyiannis, P. V., Pantelakis, Sp. G. (2005) Fatigue and damage tolerance behaviour of corroded 2024 T351 aircraft aluminum alloy. Theor. Appl. Fract. Mec., 43, 121-132.

38. Mayer, H., Schuller, R., Fitzka, M. (2013) Fatigue of 2024-T351 aluminium alloy at different load ratios up to $10^{10}$ cycles. Int. J. Fatigue, 57, 113-119.

39. Merati, A. (2005) A study of nucleation and fatigue behaviour of an aerospace aluminum alloy 2024-T3. Int. J. Fatigue, 27, 33-44.

40. Zhai, T., Jiang, X. P., Li, J. X., Garratt, M. D., Bray, G. H. (2005) The grain Boundary geometry for optimum resistance to growth of short fatigue cracks in high strength Al-alloys. Int. J. Fatigue, 27, 1202-1209.

41. Petit, J., Kosche, K. (1992) Stage I and stage II propagation of short and long cracks in Al-Zn-Mg alloys. In: Short fatigue cracks (edited by Miller, K. J., de los Rios, E. R.). ESIS 13 Mechanical Engineering Publications: London, 1992, pp. 135-151.

42. AMS Handbook Volume 12 Fractography. 9th ed., ASM International, Handbook Committee: United States, 1987.

43. Cini, A., Irving, P. E. (2010) Transformation of defects into fatigue cracks; the role of Kt and defect scale on fatigue life of non-pristine components. Procedia Eng., 2, 667-677.

44. Nowell, D., Dini, D., Duò, P. (2003) Stress analysis of V-notches with and without cracks with application to foreign object damage. J. Strain Anal. Eng., 38(5), 429-441.

45. Frost, N. E., Marsh, K. J., Pook, L. P. (1974) Metal fatigue. Oxford University Press: Oxford.

46. Edwards, P. R., Earl, M. G. (1975) A comparative study of the fatigue performance of notched specimens of clad and unclad aluminium alloy, with and without pre-stress. Royal Aircraft Establishment TR 75148, Dec 1975.

47. Schijve, J., Jacobs, F. A., Tromp, P. J. (1976) The significance of cladding for fatigue of aluminium alloys in aircraft structures. NLR TR 76065 U.

48. Taylor, D. (1986) Fatigue short cracks: the limitations of fracture mechanics. In: The behaviour of short fatigue cracks (edited by Miller, K. J., de los Rios, E. R.). EGF Pub. 1 Mechanical Engineering Publications: London, 1986, pp. 479-490.

49. Cunningham, S., Fawaz, S., Harter, J. A., Litvinov, A., Newman, D., Wu, H. R. (2004) AFGROW Material Database version 4.0009e.12, downloadable computer software, United States Air Force.

50. Irving, P. E., Hopper, B., Scott, A. J. (2005) Investigation of the effect of machined scratches on fatigue life of clad 2024-T351. Canfield University Report for Airbus ABH1, Dec 2005.

51. Morency, R. (2006) Fatigue crack initiation and growth from scratches in 2024 T-351 aluminium. M. Sc. thesis, Cranfield University, UK. 
52. Walmsley, S. W. (2007) Fatigue potential of tool scratches on clad 2024-T351 aluminium alloy. M. Sc. thesis, Cranfield University, UK.

53. Jozelich, A. M. (2009) Investigation of the transformation of defects into fatigue cracks. M. Sc. thesis, Cranfield University, UK.

Table 1

\begin{tabular}{ccccccccccc}
\hline \multirow{2}{*}{ Material } & \multirow{2}{*}{$\mathrm{Si}$} & \multirow{2}{*}{$\mathrm{Fe}$} & $\mathrm{Cu}$ & \multirow{2}{*}{$\mathrm{Mn}$} & \multirow{2}{*}{$\mathrm{Mg}$} & \multirow{2}{*}{$\mathrm{Cr}$} & \multirow{2}{*}{$\mathrm{Ti}$} & \multicolumn{2}{c}{ Others } \\
& & & & & & & & \\
Al 2024-T351 & 0.50 & 0.50 & $3.8-4.9$ & $0.3-0.9$ & $1.2-1.8$ & 0.10 & 0.25 & 0.15 & 0.05 & 0.15 \\
\hline
\end{tabular}


Table 2

\begin{tabular}{|c|c|c|c|c|c|}
\hline Al 2024-T351 & $\begin{array}{c}\text { Young's modulus } \\
E \\
{[\mathrm{MPa}]}\end{array}$ & $\begin{array}{c}\text { Poisson's ratio } \\
v\end{array}$ & $\begin{array}{c}\text { Yield strength } \sigma_{0.2} \\
{[\mathrm{MPa}]}\end{array}$ & $\begin{array}{c}\text { Tensile strength } \sigma_{U T S} \\
{[\mathrm{MPa}]}\end{array}$ & $\begin{array}{c}\text { Elongation } \varepsilon_{f} \\
{[\%]}\end{array}$ \\
\hline Unclad LT ${ }^{34}$ & 72000 & 0.33 & 360 & 481 & 19 \\
\hline Clad $\mathrm{LT}^{35}$ & $65500 \leq E \leq 70500$ & 0.33 & 280 & 425 & 15 \\
\hline
\end{tabular}


Table 3

\begin{tabular}{|c|c|c|c|c|c|c|c|}
\hline \multirow[b]{2}{*}{ Sample } & \multicolumn{2}{|c|}{ Scribe } & \multicolumn{3}{|c|}{ Fracture front } & \multicolumn{2}{|c|}{ Nucleation points } \\
\hline & $\begin{array}{c}d \\
{[\mu \mathrm{m}]}\end{array}$ & $\begin{array}{c}\rho \\
{[\mu \mathrm{m}]}\end{array}$ & Type & Crack number & Main crack shape & Number & $\begin{array}{l}\text { Density } \\
{[1 / \mathrm{mm}]}\end{array}$ \\
\hline T-C-0-0 & - & - & 1 elliptical & 1 & corner & 1 & 0.01 \\
\hline T-C-25-5 & 25 & 5 & multiple cracks & 10 & surface & 221 & 2.76 \\
\hline T-C-50-5 & 50 & 5 & coalesced & 1 & through & 603 & 7.54 \\
\hline T-C-100-5 & 100 & 5 & elongated & 1 & through & 681 & 8.51 \\
\hline T-C-150-5 & 150 & 5 & elongated & 1 & through & 731 & 9.14 \\
\hline T-C-185-5 & 185 & 5 & elongated & 1 & through & 793 & 9.91 \\
\hline T-C-25-25 & 25 & 25 & multiple cracks & 8 & surface & 33 & 0.41 \\
\hline $\mathrm{T}-\mathrm{C}-50-25$ & 50 & 25 & multiple cracks & 7 & corner & 165 & 2.06 \\
\hline T-C-100-25 & 100 & 25 & coalesced & 1 & through & 499 & 6.24 \\
\hline T-C-150-25 & 150 & 25 & coalesced & 1 & through & 572 & 7.15 \\
\hline T-C-185-25 & 185 & 25 & coalesced & 1 & through & 588 & 7.35 \\
\hline T-C-25-50 & 25 & 50 & multiple cracks & 5 & surface & 15 & 0.19 \\
\hline T-C-50-50 & 50 & 50 & multiple cracks & 15 & corner & 38 & 0.48 \\
\hline T-C-100-50 & 100 & 50 & coalesced & 1 & through & 210 & 2.63 \\
\hline T-C-150-50 & 150 & 50 & coalesced & 1 & through & 332 & 4.15 \\
\hline T-C-185-50 & 185 & 50 & coalesced & 1 & through & 547 & 6.84 \\
\hline
\end{tabular}




\section{Table 4}

\begin{tabular}{|c|c|c|c|c|c|}
\hline \multicolumn{4}{|c|}{ Scribe geometry } & \multicolumn{2}{|c|}{$K_{t}=\frac{\sigma_{22}^{\text {root }}}{\sigma_{\max }}$} \\
\hline $\begin{array}{c}d \\
{[\mu \mathrm{m}]}\end{array}$ & $\begin{array}{c}\rho \\
{[\mu \mathrm{m}]}\end{array}$ & $\begin{array}{c}\theta \\
{\left[{ }^{\circ}\right]} \\
\end{array}$ & $\begin{array}{c}\text { Aspect ratio } \\
\rho / d\end{array}$ & Tension & Bending \\
\hline 25 & 5 & 60 & 0.200 & 5.88 & 5.77 \\
\hline 50 & 5 & 60 & 0.100 & 8.07 & 7.76 \\
\hline 100 & 5 & 60 & 0.050 & 11.27 & 10.42 \\
\hline 150 & 5 & 60 & 0.033 & 13.95 & 12.34 \\
\hline 185 & 5 & 60 & 0.027 & 15.70 & 13.44 \\
\hline 25 & 25 & 60 & 1.000 & 3.07 & 3.01 \\
\hline 50 & 25 & 60 & 0.500 & 4.02 & 3.86 \\
\hline 100 & 25 & 60 & 0.250 & 5.44 & 5.01 \\
\hline 150 & 25 & 60 & 0.167 & 6.64 & 5.84 \\
\hline 185 & 25 & 60 & 0.135 & 7.44 & 6.32 \\
\hline 25 & 50 & 60 & 2.000 & 2.43 & 2.38 \\
\hline 50 & 50 & 60 & 1.000 & 3.09 & 2.96 \\
\hline 100 & 50 & 60 & 0.500 & 4.08 & 3.74 \\
\hline 150 & 50 & 60 & 0.333 & 4.93 & 4.31 \\
\hline 185 & 50 & 60 & 0.270 & 5.49 & 4.64 \\
\hline
\end{tabular}


Fig 1

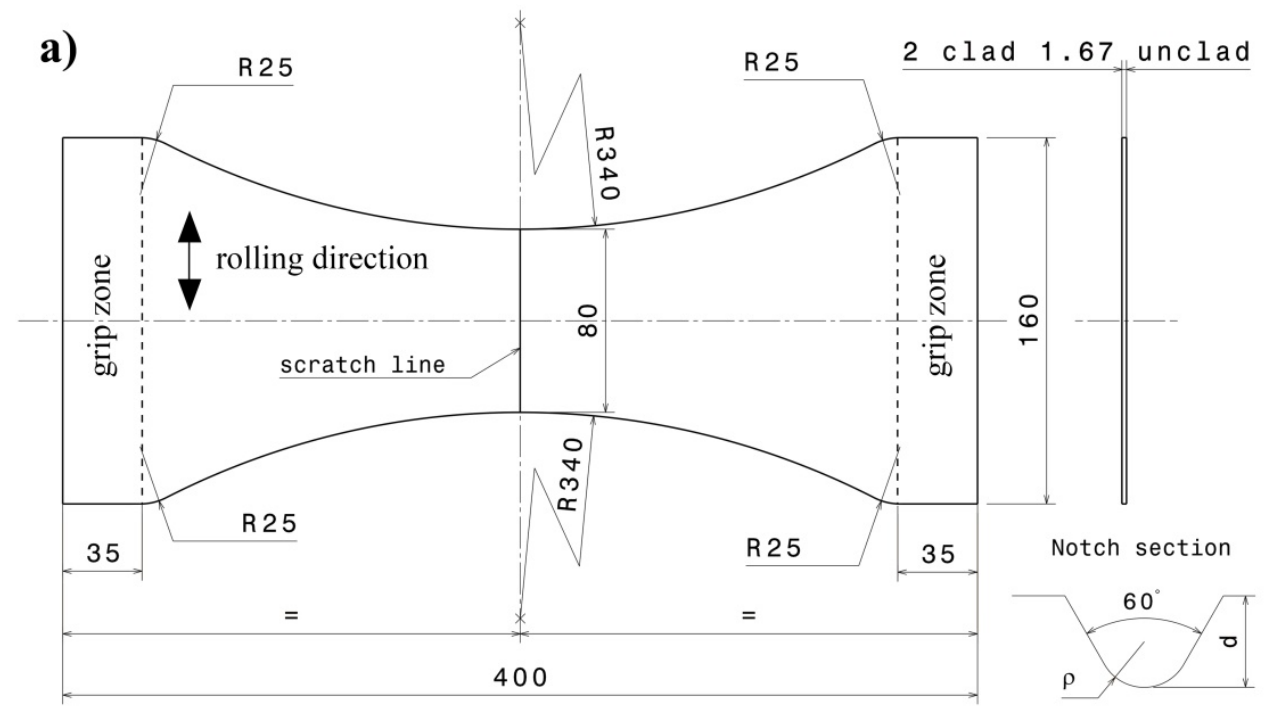

b)

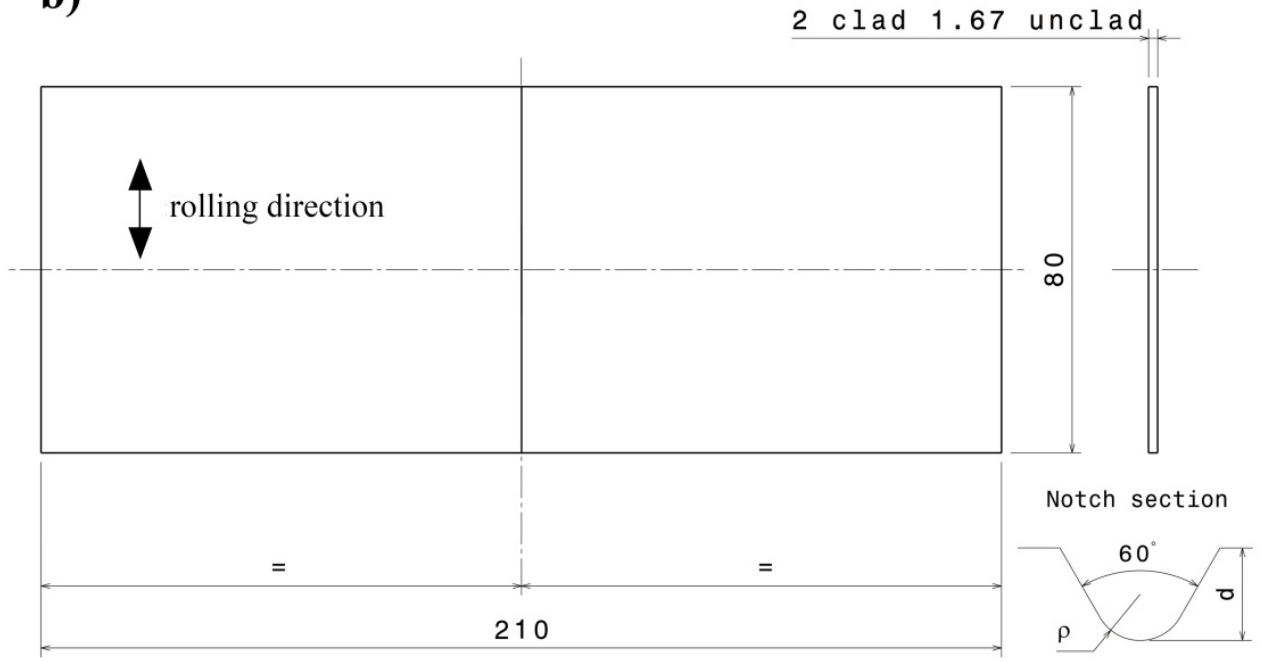


Fig 2
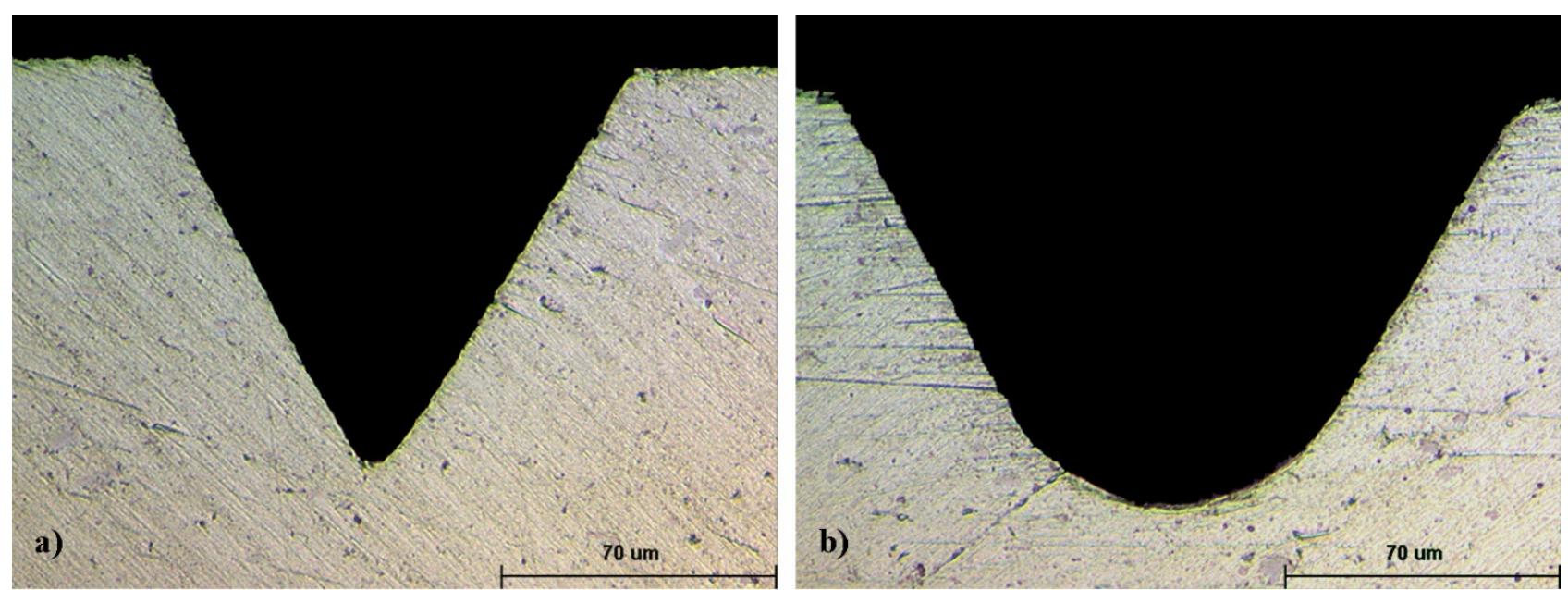
Fig 3

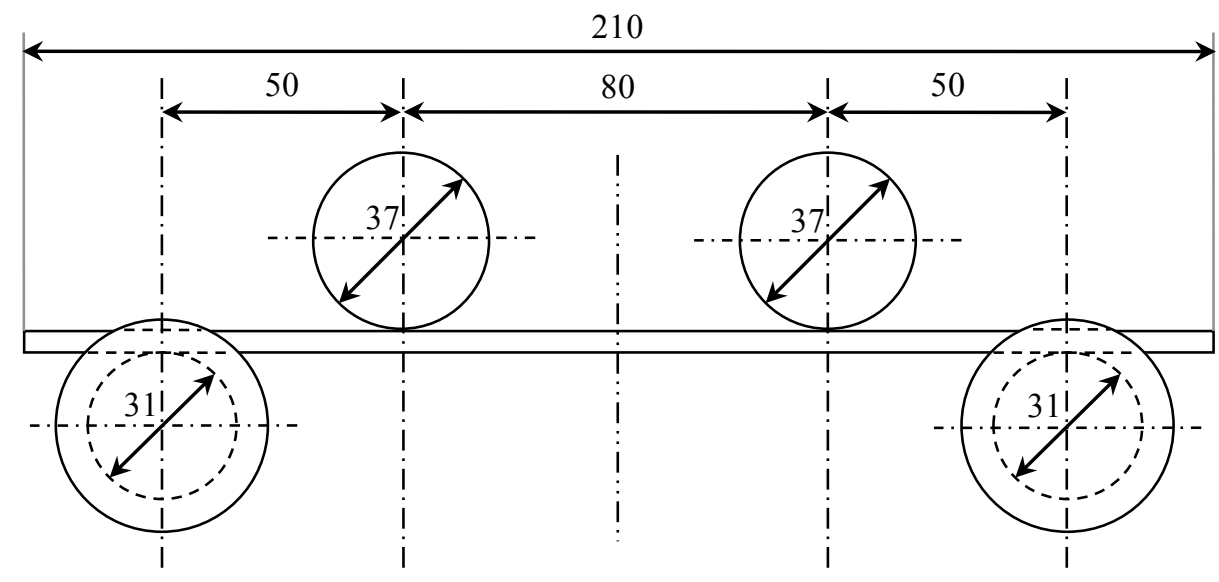


Fig 4
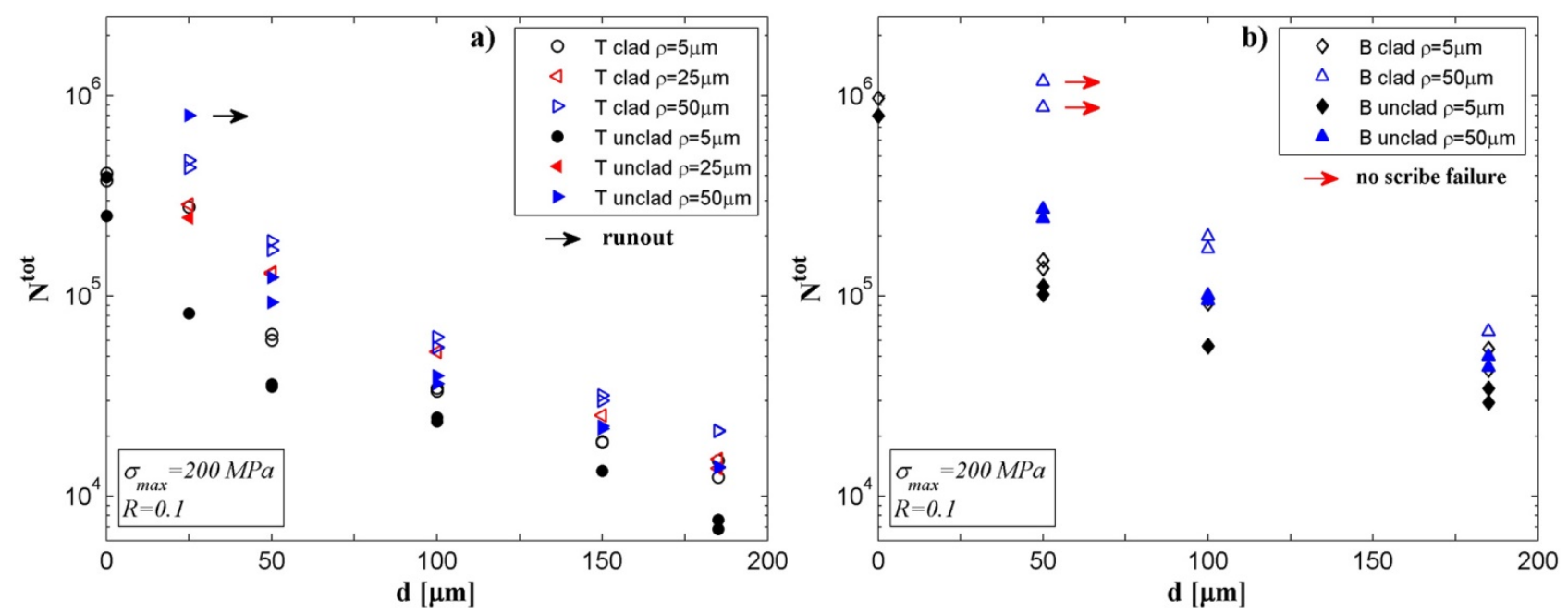
Fig 5

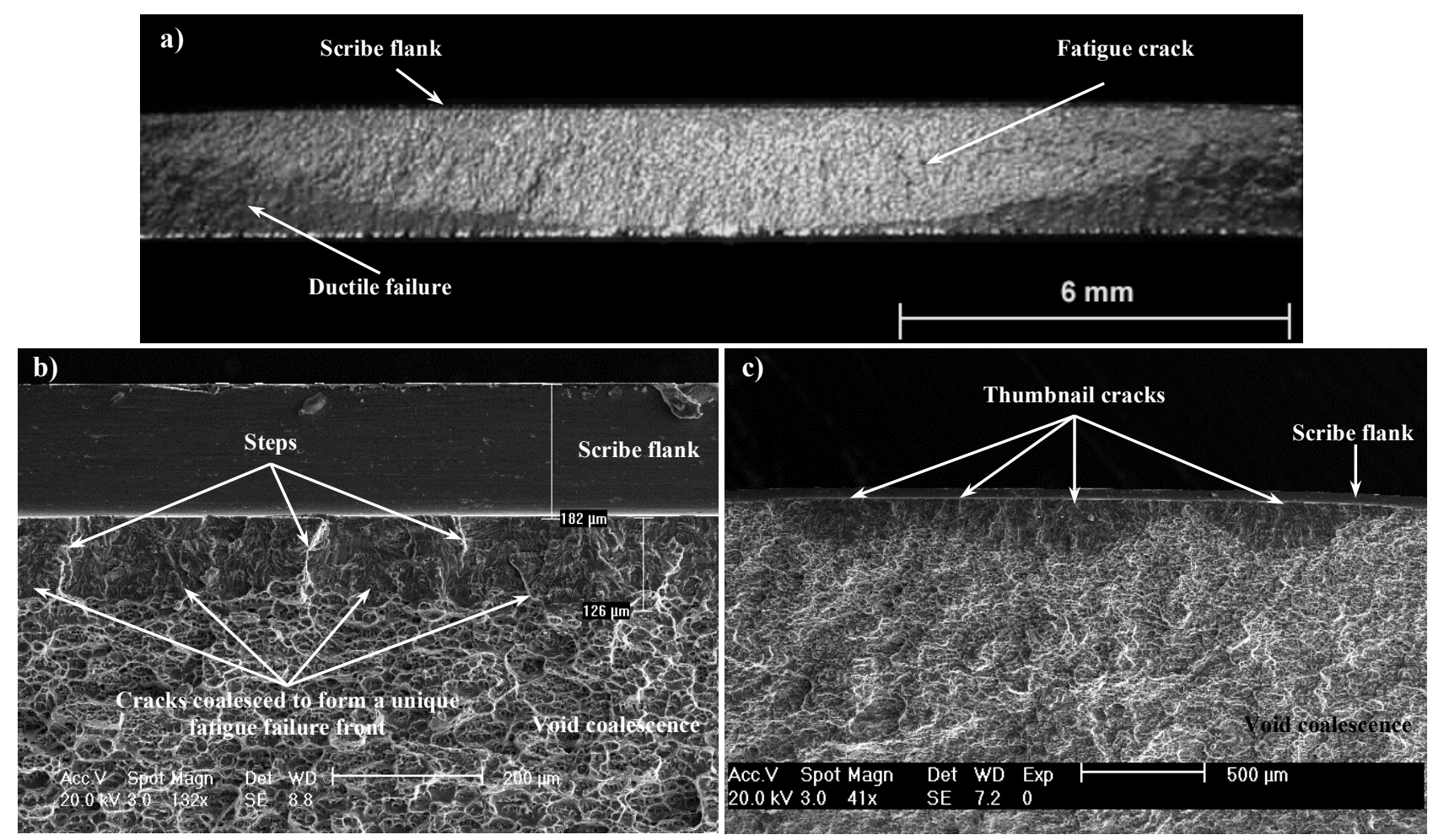


Fig 6
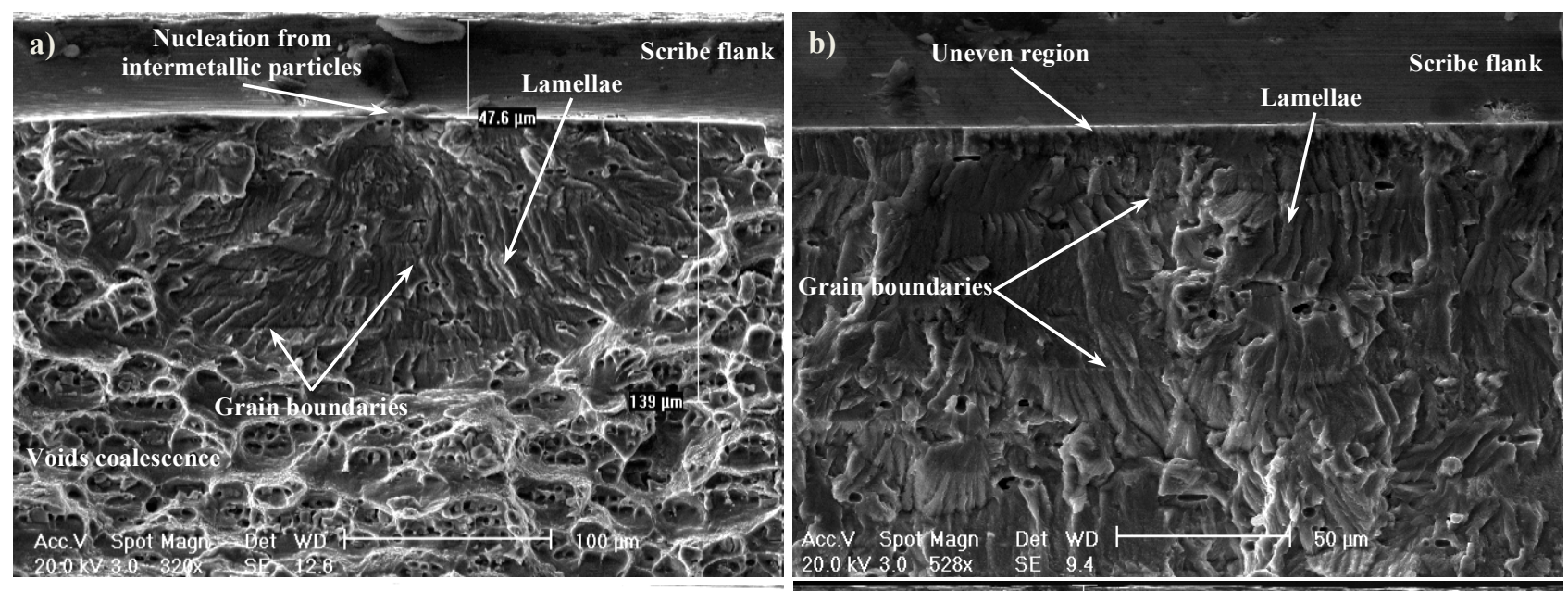

c) Uneven region
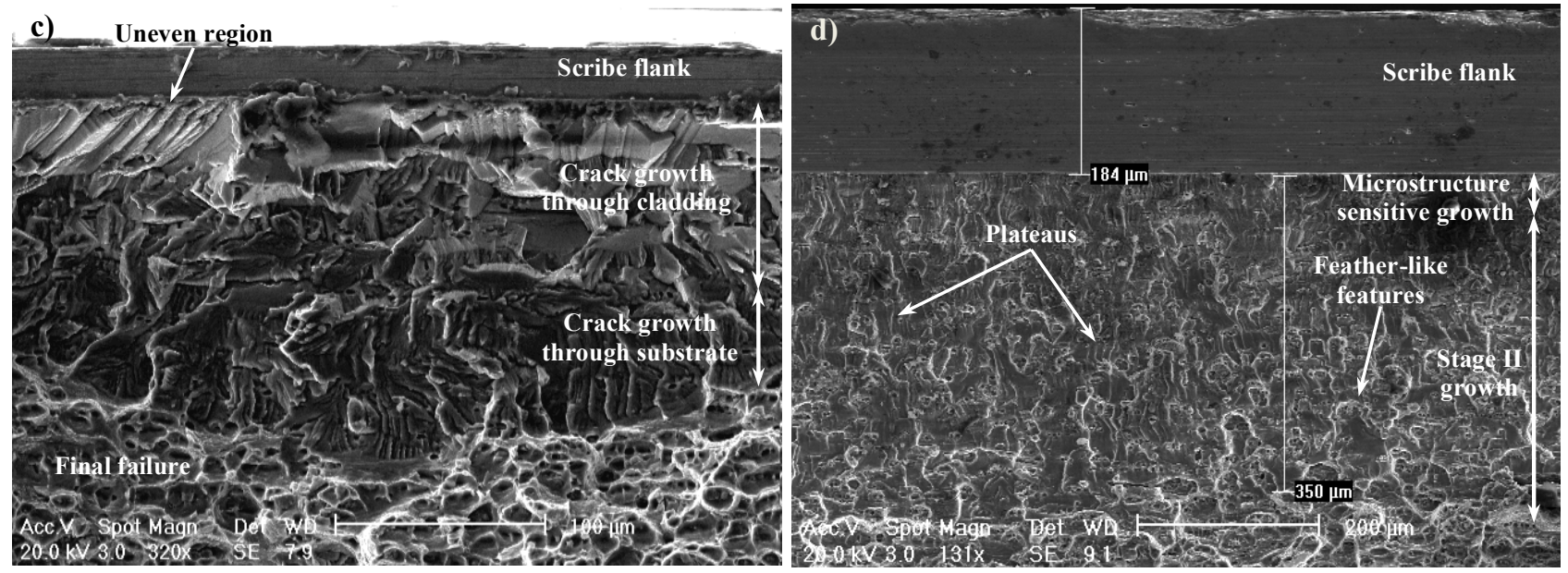
Fig 7

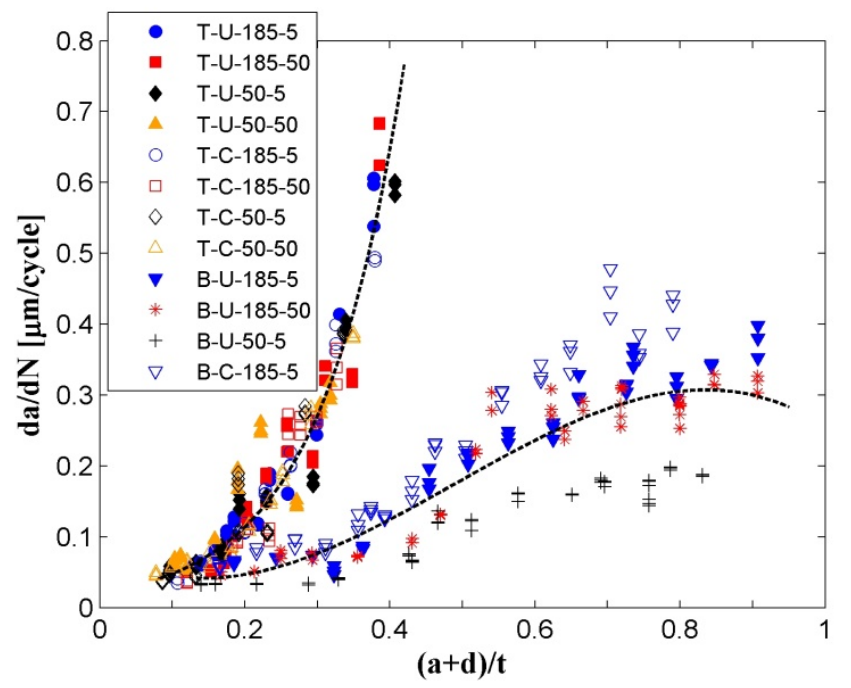


Fig 8
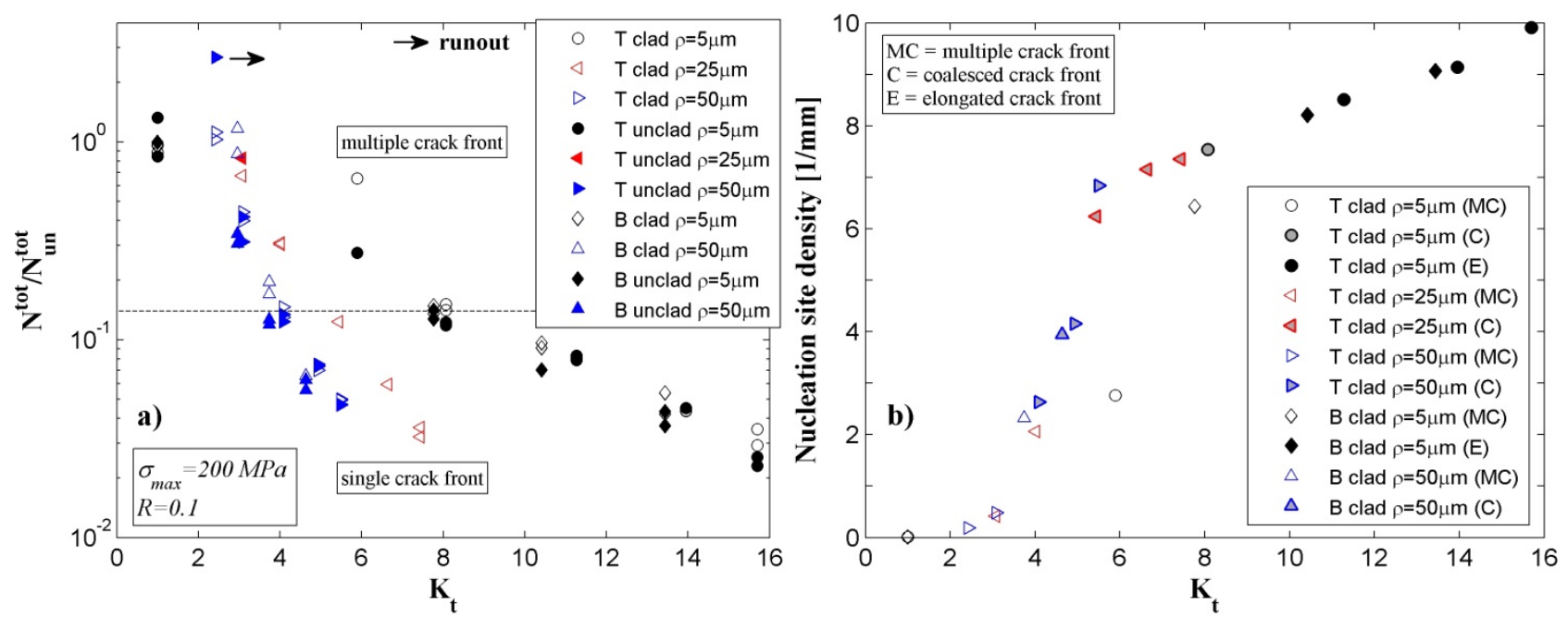
Fig 9

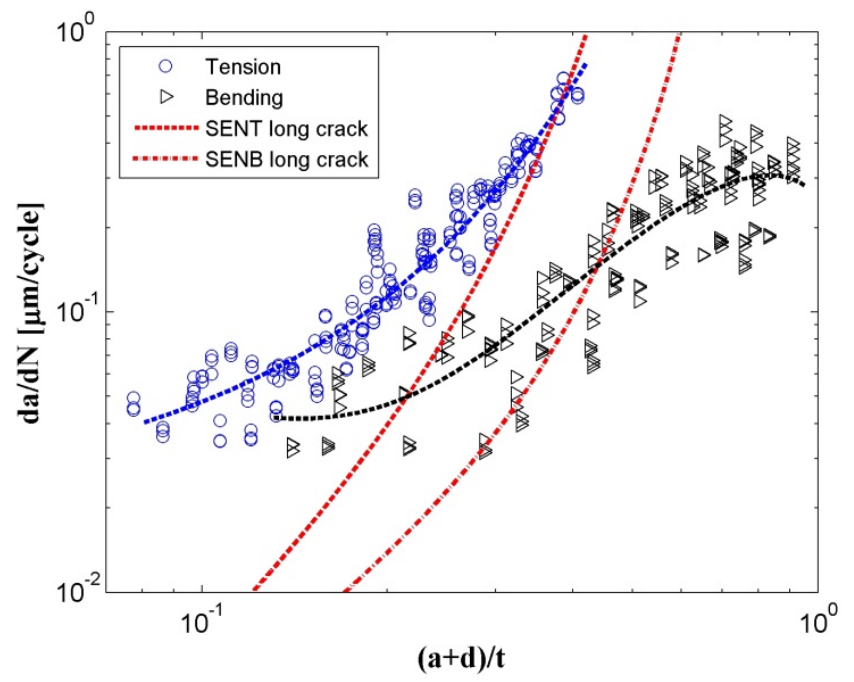


Fig 10
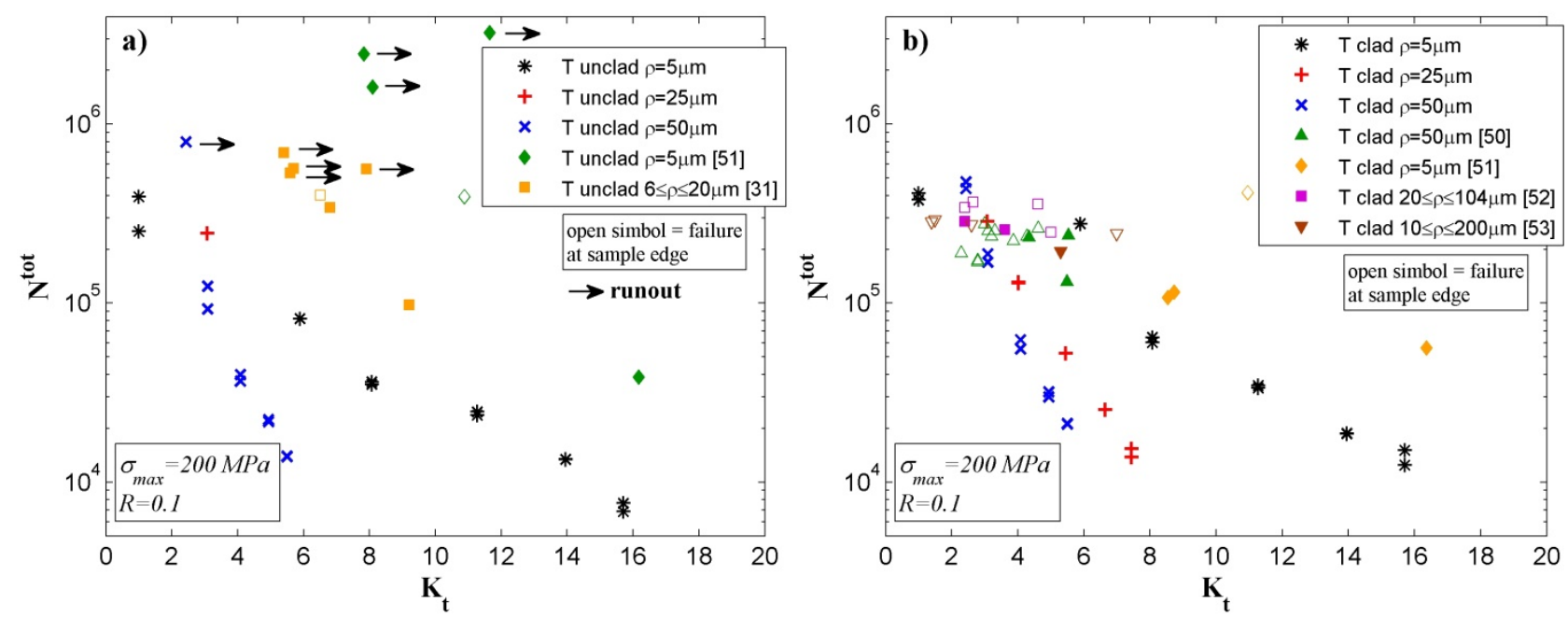
Fig 11

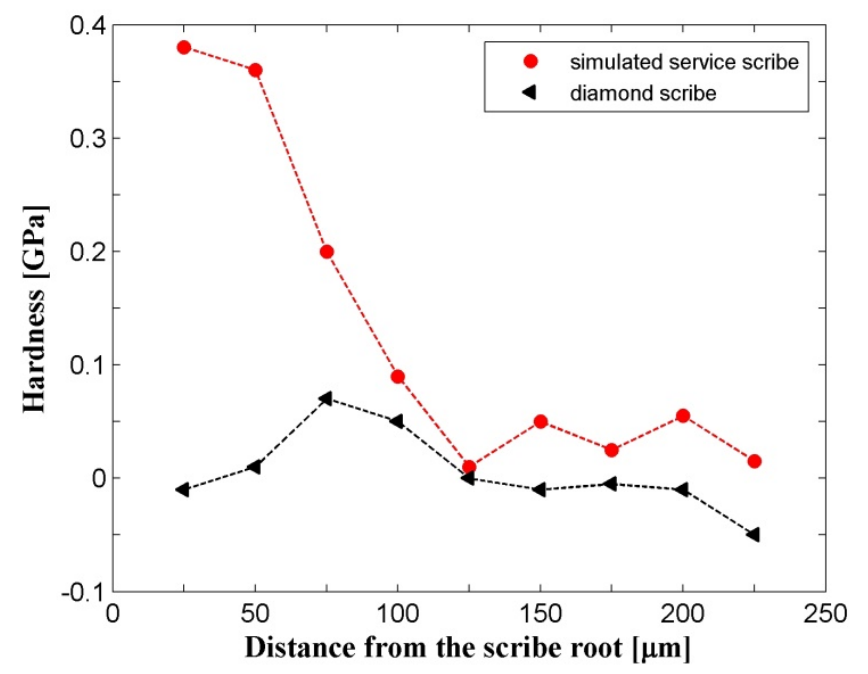




\section{Development of fatigue cracks from}

mechanically machined scratches on 2024-T351 aluminum alloy - Part 1: experimentation and fractographic analysis

Cini, Andrea

Wiley

Cini, A., and Irving, P. E. (2016) Development of fatigue cracks from mechanically machined pÿscratches on 2024-T351 aluminium alloy part I: experimentation and fractographic analysis. Fatigue and Fracture of Engineering Materials and Structures, Volume 40, Issue 5, 2017, pp. 776-789 http://dx.doi.org/10.1111/ffe.12544

Downloaded from Cranfield Library Services E-Repository 